\title{
Objective reality of subjectivity: descriptors of sociality
}

\author{
Aleksandr Fedoseenkov* \\ Don State Technical University, 344006, Rostov-on-Don, Russia
}

\begin{abstract}
The article discusses the features of psychological states in the context of the overall development of human culture. Culture is a combination of material and spiritual values accumulated by mankind in the process of development and a way of establishing social and personal interaction, that is, a way of suppressing or developing society of certain personality traits. Culture, being an extremely broad concept, has the status of a philosophical category, since it contains all the variety of semantic contexts created by three main worldviews: religion, science and philosophy.
\end{abstract}

\section{Cultural traditions of subjectivity}

The primary (primitive, or rather "primative", from the Latin word prima) form of human attitude to the world - a primitive worldview is mythology, the basis of which is considered to be a feature of human awareness of the surrounding reality, not only in indissoluble unity with itself, but also possessing spiritual properties. The next form of reality awareness - was the primitive religion, which not only tried to explain, to the best of its ability, the formation and structure of the world, but also foresaw a certain rhythm of interaction with the surrounding reality. A man learned not only to take, but also to give, since he could and considered it necessary - in the form of a sacrifice. Primitive religion differed from modern forms in which it was polytheistic, that is, there was enough room for several gods, without the clearly expressed dominant position of one of them [12].

\footnotetext{
* Corresponding author: afedo60@,mail.ru
} 
For survival, a person needs not only the creation of biological environment conditions, but also mental conditions. He must maintain some mental balance in order to maintain the ability to perform his functions. For a person, everything that contributes to mental comfort is as important in a vital sense as whatever serves biological equilibrium [1]. The main human interest is the preservation of its coordinate system based on value orientation. The ability to act, and, ultimately, the realization of oneself as a person, also depends on it. If a person discovers ideas that question his own value orientations, he will perceive them as a threat to his vital interests. Rejecting unacceptable ideas, a person will try to give a rational interpretation of this. In fact, rejection has only one basis - a sense of threat from the outside. That is why the etymological preamble of the word "non-property" comes from the denial of "not your own." In his development, the person needs not only the coordinate system necessary for emotional balance, but also the freedom to choose preferences [5]. In order for a person to be extremely adequate, knowledge of a psychological nature is necessary - a component without which a modern person and his own freedom are impossible.

Psychological culture is the focus of the personality's mental activity including value development guidelines. The physical and mental health of a person affects the quality of life, a problem has arisen of adapting the human psyche to constantly complicated social technologies for the development of living space, in which uncertainty and risk can prevail. This requires the problem development of increasing the creative potential of a person, the development of his abilities for creativity and imagination [6], the removal of stressful situations.

\section{The primitive experience of the personality socialization}

Gradually and consistently, biological marginality, which played a leading role in the development of human nature, is replaced by primitive forms of social marginality [10]. During the transition of a person from biological existence to the priorities of social life, the individual significance of the marginality subject is measured by the role played by the individual in the primitive community. The inner life of an individual, as a carrier of personal psychological characteristics, in a primitive society is almost completely absent [8]. But here, for the first time, a new quality manifests itself, bearing the significance of the axiological aspect of social life - marginality, for which, in a primitive society there is a liminal period. A change in the essence of human nature depends not only on external spatial habitats, but also corresponds to a certain cyclical nature of changes in social phases [13]. This period of human identity development stands out as liminal.

The change in social position and status was noted by the laminarity researcher $\mathrm{V}$. Turner in three phases: 1) separation; 2) face (margo, or limen, which in Latin means "threshold") and 3) restoration (reaggregation). The first phase means the detachment of 
an individual or an entire group from a previously occupied place in the social structure and from certain cultural circumstances, or from both at once. The second phase - the "liminal" period, is intermediate; in it the transitional subject receives duality features, because it resides in the area of culture in which there are very few or no properties of the past or future states. The third phase is restorative and completes the transition. The transitioner regains a stable state and thanks to this receives the rights and obligations of a structural type, which force him to build his behavior in accordance with the usual norms and ethical standards [9].

The greatest importance is the intermediate phase, in which the properties of "threshold" people, often called liminal persons, are thoroughly clarified. These people are ambivalent because they do not fit into the framework of any classifications [15] that place states and positions in the cultural space. According to V. Turner, a characteristic feature of liminal existence is that these people are neither here, nor there, neither this, nor that, they are in crevices and gaps. The marginal properties of ambivalence are expressed by a wide variety of symbols, and linality is often likened to death, uterine existence, invisibility, darkness, bisexuality, desert, eclipse of the Sun and Moon [9].

Liminal creatures, for example, neophytes in rites of initiation or adulthood, are represented as possessing nothing. They dress up as monsters, wear tattered clothes or walk naked, demonstrating that they do not have status, property, insignia, secular clothing indicating their place and role, position in the kinship system; in short, nothing that could distinguish them from other neophytes or initiated. Their behavior is usually passive or humiliated; they must implicitly obey their mentors or accept unfair punishment without complaint. It seems that they are relegated and belittled to complete uniformity, in order to gain a new look and be re-formed and endowed with new forces that would help them get used to their new position in life. Between themselves, the neophytes strive to establish partnerships and equality. Secular differences in position and status disappear and are homogenized.

In the primitive experience of social marginality, considered in this context as liminality, the features of an alternative to structure are manifested in order to better understand the structure itself. In such rites, a moment is given in time and outside it, as well as inside and outside the secular social structure, which reveals, although fleetingly, the recognition (in the symbol, if not always in the language) of the universal social connection, already interrupted and already at the same time ready for fragmentation to many structural bonds. In the characterization of concepts given by V. Turner, such relations are formed in terms of either "caste" and "class", or "job hierarchy", or "segmental opposition" in stateless societies [9]. There are, as it were, two models of human interconnectedness, overlapping and alternating. The first is a model of society as a structural, differentiated and often hierarchical system of political, legal and economic provisions with many types of assessments that separate people on the basis of "more" or "less". The second is distinguishable only in the liminal period - a model of society as an 
unstructured or rudimentary-structural and, comparatively, undifferentiated comitatus community, or even a community of equal personalities subordinate to the supreme power of ritual elders.

\section{Personal limit: personalization and personification}

Personality is a relationship acquired by an individual in the process of communication and activity, characterized by inclusion in spiritual reproduction, through the desire to go beyond the existing social limitations [7].

M. Bakhtin called the atmosphere of deep confidence of an outgoing spirit from outside the "gracious" excuse for life [2]. This is the area in which life discharges its dense energies, translating the subjective infinity of the personality (person) into the objective finiteness of a thing. "Two limits of thought and practice (deed) or two types of relationships (thing and personality). The deeper the personality, that is, closer to the personal limit, the more inappropriately generalizing methods, generalization and formalization blur the boundaries between genius and mediocrity ... the process of materialization and the process of personalization. But personalization is by no means subjective. The limit here is not me, but I am in a relationship with other personalities, that is, I and the other, me and you ... our thought and our practice is not technical, but moral (that is, our responsible actions), are made between two limits: relations to things and personal relationships, reification and personification. Some of our acts (cognitive and moral) strive to the limit of materialization, never reaching it, other acts - to the limit of personification, not reaching it to the end" [2].

Two limits of thought, forming two inapplicable to each other methodologies - two relations to the world: generalization and formalization, which give rise to the processes of materialization and personalization. At the same time, one should not forget that a thing and a person are limits, and not absolute substances. In this procedural relationship, a person is a boundary, a marginal zone in which, becoming personalized, he becomes a person, or, recreating the process of materialization associated with formalization, becomes a thing - a "dumb witness to events" [2].

Personalization is associated with a special kind of creative consciousness personification, which often unites and personifies other people's voices that become anonymous into special symbols: the voice of life itself, the voice of nature, the voice of the people, the voice of God. In a state of "personalized" marginality, a person translates his spiritual aspirations (often, perhaps, illusions) of external life into the internal setting of a personified personality, which introduces into the eternal, causal relations of formalized activity and, thus, to the interpretation of the world of being in logical categories. In this, the human desire manifests itself, according to M. Bakhtin, to embody out-of-place anonymous contexts (to surround oneself with out-of-place life). 
The phenomenon of personalization opens up the possibility of explaining the always existing human problem of personal immortality [14]. If a person's personality is not reduced to its representation in a holistic subject, but continues in other people, then with the death of an individual, the person "does not completely" die. In the words "he lives in us and after death" there is neither mysticism nor pure metaphoricality - this is a statement of the destruction fact of a holistic psychological structure while maintaining one of its links.

\section{The cultural evolution of personality}

Cultural evolution has its own driving force, different from the driving forces of organic evolution. Cultural evolution can be considered a completely independent process, although in practice it interacts with organic evolution. In the study of cultural evolution it is studied separately, however, in any study of humanity, it is more correct to consider modern human as a product of the combined action of organic and cultural evolution [4].

If we consider human as one of the representatives of mammals and higher primates, then he should be considered a product of organic evolution; however, human, as a representative of humanity, is a product of both organic and cultural evolution. In addition, those truly identifiable signs of a person by which he differs from an animal developed in the process of cultural evolution. The opposition of cultural and organic evolution at the present stage of the human continuum development is the main (it should be distinguished from the main) contradiction of the evolutionary development of the planet as a whole. The interaction of these opposites is the prospect of the existence of not only humanity itself, but also forms of modern life on the planet as a whole for the coming centuries [6]. The global problem of war and peace facing humanity several years ago is being pushed aside by the problems of the relationship between humanity and nature: environmental, demographic, energy.

Each individual at birth is endowed with the constitution of an animal belonging to primates, but is devoid of any culture. Culture is acquired in the process of individual development as a result of training in a broad sense. In the first years of development, a person from the state of a humanoid animal, at birth, passes through the stage of a barbarian (child) into the human state in the true or diagnostic meaning of the word "human" [2]. And this, the mental development of the individual, occurs as a result of the formative influence of social factors and education. "The individual perceives the culture in which he (or she) was born and raised, not counting the rare cases when the individual is able to think independently and singly and transcends the boundaries of his native culture; however, even in these cases, to a certain extent, he preserves this culture" [4]. In this statement, V. Grant considers the tendency to the ability of individuals, who, according to Mayr, constitute $12.5 \%$ in the organic world, to the preservation and 
development of culture as a whole through the ability to view their own cultural evolution under the prism and from the perspective of other distinctive cultures. It is they who "changing" their culture creates the prerequisites for further cultural convergence.

Successively passing through the stages of organic evolution a person simultaneously, but not later and after, goes through the stages of cultural evolution [12]. And the sooner these stages, when combined, begin to form joint links, the sooner a person acquires his own intermediateness and, as a result, a marginal state. This can cause (and causes) a state of discomfort and dissatisfaction with oneself, because the human mindset seeks to know the only multiplicity - itself [15]. It is this ability of thinking that a person differs from animals. The way out of oneself from one's organic nature in order to find oneself in the culture of society and to see oneself with different eyes and the eyes of others. "In the light of evolutionary biology, man is a mammal, or rather a primate, more precisely - a humanoid, and more precisely - a representative of anthropoids of a very highly developed type. These successive stages, or cities, of organic evolution are embedded in the human body" [4]. Cultural evolution adds another layer, in a certain context - a series of layers, to human nature. The dual constitution - partly biological, and partly cultural, is laid down in humanity by evolutionary development, in which the uppermost layer is the decisive layer by which a person differs from an animal.

\section{Conclusion}

Social dependence was dictated by the high biological interaction between heterosexual individuals [3]. An increase in brain size beyond certain limits led to a state of biological marginality. The selection for high intelligence came into conflict with the selection for the survival of a woman during childbirth, which was hampered by the width of the birth canal through which the baby's head should pass during childbirth. In order to break the deadlock, biological transformations were required that determined the further cultural evolution of human sociality. The first transformation was the expansion of the pelvis in a woman, which entailed a loss of speed when running. This was the first sacrifice made by the nature of a woman so that she could give birth to children with a more voluminous brain. The second transformation was to reduce the rate of brain development. By the time of birth, the human brain is not yet formed. Brain development occurs mainly in the juvenile period of infancy and childhood. This led to an increase in the duration of the stages of individual development preceding the onset of maturity [8]. In both cases, biological transformations have reduced the independence of women. She was burdened with worries about the child for a longer time. The social maturation of an individual, associated with longer periods in mastering the experience of previous generations, also implies a longer children's period of developing personality [12]. This forced social prolongation for the individual, more and more stretched with the increase in the cultural 
context of sociality as a developing form, also increases the state of individual marginality [10]. In principle, natural selection accompanying the entire preceding evolutionary process was gradually replaced by social selection.

Social selection is as much a natural development process as organic. This is a selection of a higher level corresponding to the highest ordering of all known forms of differentiation [7]. As a criterion for further selective selection, the organic form of human nature has exhausted itself, since it has ceased to regulate the fundamental relationship between nature and man. Already, society puts a separate individual in various conditions of existence, often extreme, revealing a latent selective potential.

\section{References}

1. A. Adler, Understand the nature of man (St. Petersburg, 1997).

2. M.M. Bakhtin, Aesthetics of verbal creativity, Sost. S. G. Bocharov (Art, Moscow, 1979).

3. E. Bern, Games that people play (Moscow, 1997).

4. V. Grant, The evolutionary process: A critical review of evolutionary theory (Mir, Moscow, 1991)

5. M. James, D. Jongward, Born to win (Moscow, 1993).

6. E.V. Ilyenkov, What is a personality (Philosophy and culture, Moscow, 1991).

7. A. Maslow, The far reaches of the human psyche (Moscow, 1997).

8. E.B. Taylor, Primitive culture (Moscow, 1989).

9. V. Turner, Symbol and ritual (Comp. V.A. Beilis, Moscow, 1983).

10. A.V. Fedoseenkov, Psychological culture: overcoming subjective limitation (Rostovon-Don, 1999).

11. E. Fromm, Anatomy of human destructiveness (Moscow, 1994).

12. D. Hillman, Archetypal Psychology (St. Petersburg, 1996).

13. A. Schopenhauer, The concept of will (Selected works, Comp. I.S. Narsky, Moscow, 1992).

14. K. Jung, Analytical Psychology (St. Petersburg, 1994).

15. K. Jaspers, General psychopathology (Moscow, 1997). 